\title{
Toxoplasmosis in Small Ruminants from Varied Habitats
}

\author{
Saghir Ahmad*, ZahidaTasawar \\ Institute of Pure and Applied Biology, Bahauddin Zakariya University, Multan, Pakistan
}

Email address:

saghirahmad@bzu.edu.pk (S. Ahmad), saghir7np@yahoo.com (S. Ahmad)

\section{To cite this article:}

Saghir Ahmad, Zahida Tasawar. Toxoplasmosis in Small Ruminants from Varied Habitats. Animal and Veterinary Sciences. Vol. 3, No. 4, 2015, pp. 120-124. doi: 10.11648/j.avs.20150304.15

\begin{abstract}
Background: Toxoplasmosis is an infectious disease found all over the world in all the mammalian and avian species. We conceived the hypothesis that the infection might be affected by the various factor differing in various habitats. The present study was conducted to evaluate our hypothesis by investigating the rates if infections different flocks of small ruminants populated in various localities with varied ecological conditions in southernmost part of Punjab, Pakistan. Materials and Method: The blood samples collected from mixed farms of sheep and goats were examined by Latex Agglutination Test to detect rates of seroprevalence of anti-Toxoplasma antibodies. Statistical analyses were applied to ascertain the correlation between habitat variations and rates of toxoplasmosis in three distinct regions of study area including sand dunes of Cholistan desert, Agricultural Region and Marshy areas. Results: The total infection rates collectively found in small ruminants were $31.41 \%$. The incidence rates of Toxoplasma infection in small ruminants were $38.1 \%, 32.1 \%$ and $14.5 \%$ in animals reared in Agricultural Region, Riverside region and Sand Dunes region of Cholistan correspondingly. Conclusions: The results showed the varied rates of toxoplasmosis in small ruminants in various habitats in the study area. Furthermore, the overall higher occurrence of toxoplasmosis in small ruminants underlined the threat of zoonotic transmission of infection to human.
\end{abstract}

Keywords: Toxoplasmosis, Small Ruminants, Habitat Variations

\section{Introduction}

The Domestic sheep and goats are the vital source of milk, meat, fibers and pelts in almost all the countries of the world. These livestock animals are vulnerable to different parasitic diseases (Gebremedhin et al., 2013) including toxoplasmosis (Othman and Al-Azuheir, 2014) that causes a range of reproductive problems such as prenatal and postnatal mortality, still births or abortions (Edwards and Dubey, 2013) leading to the economic losses and threats to human health via zoonotic transmission (Othman and Al-Azuheir, 2014). The livestock animals in general and small ruminants in particular are exposed to a variety of infectious and noninfectious diseases of parasitic origin (Akhter and Arshad, 2006; Siddiki et al., 2010) leading to the reduction in productivity (Haileleul, 2002). Parasitic infections pose threats to health and limit the productivity due to the associated morbidity and mortality (Nwosuet al., 2007) or due to early death in the embryonic life, mummification, abortion, stillbirth (Panadero et al., 2010), and in some cases the neonatal or postnatal death (Edwards and Dubey, 2013). These infections have become a serious universal threat for livestock (Lashari and Tasawar, 2011).
One of these infections is toxoplasmosis caused by Toxoplasma gondii (hereafter referred as T. gondii or/and Toxoplasma) belonging to class Coccidia of phylum Apicomplexa (Ferguson, 2002; Kopecna et al., 2006). T. gondii is widespread in distribution and can be considered as one of the most successful protozoan parasites (Doskaya et al., 2006) that can inflict serious diseases in all the endothermic animals (Doskaya et al., 2006; Dubey, 2009) such as mammals including small ruminants and humans (Aspinall et al., 2002). Since Toxoplasma is transmitted through zoonosis particularly from sheep and goats (Sevgili et al., 2005), there is dire need to screen the animals whose meat is used by human as food so that the human health is ensured (Hill and Dubey, 2002; Lhafi et al., 2004).

Toxoplasmosis is deleterious in terms of both economy of a country and health of its people (Hill et al., 2005) and approximately thirty three percent of animals and human population of the world has been estimated to be infected with T. gondii at an average (Sensini, 2006) ranging between 1 and $99 \%$ rates of infections (Olivier et al., 2007). The open-air meat markets are considered as a potential source of infestation of human by T. gondii. While being transported from slaughter houses, the meat is by far contaminated with 
oocysts of $\mathrm{T}$. gondii hence resulting as a risk factor of zoonosis to human beings. The incidence of $\mathrm{T}$. gondii seroprevalence in different species of animals has been studied in many countries of the world with results varying from country to country, region to region, herd to herd and season to season. Sometimes even these results vary with variation of methodology utilized on the same herd (Yu et al., 2007). The open-air markets are common in Rahim Yar Khan and Rajan Pur regions of southern Punjab, Pakistan and create a potential source of pathogen contamination as the stray cats and dogs are usually found around the markets which, being a natural reservoir of $\mathrm{T}$. gondii, add many millions of oocysts of parasite through their excreta just within a couple of week after getting infected (Dabritz et al., 2007). Oocysts of T. gondii exhibit a characteristic resistance against a broad spectrum of disinfecting agents due to structural stability principally in warm and humid regions of the world, nevertheless having poor survival in arid and cold climatic conditions (Rorman et al., 2006).

Toxoplasmosis infection has been established as a major economic threat for sheep and goat farming industry particularly due to abortion all over the world (Buxton et al., 2007; Innes et al., 2009). This disease may also cause the monitory losses in terms of the reproductive disorders such as abortions, stillbirth, or weakness of neonates that results in death (Bueno et al., 2004; Soares et al., 2009) or adult mortality, reduced productivity in small ruminants with lower quality of wool and leather (Parthiban et al., 2005). According to the findings of Kijlstra and Jongert (2009), T. gondii is a food hazard as well.

As the survival of $\mathrm{T}$. gondii is affected by environmental factors (Chacin-Bonilla and Sanchez-Chavez, 2000; Hill et al., 2005), we chose to conduct the current study to ascertain the variations in the rates of infections in the animas populated the remote areas of Pakistan. The present study is based on the research conducted to ascertain the association between toxoplasmosis in small ruminants'flocks reared in different habitat of Southern Punjab, Pakistan.

\section{Materials and Methods}

A total of 1200 blood samples were randomly collected from domestic small ruminants belonging to different localities in Cholistan Sand Dunes region, Agricultural region of district Rahim Yar Khan and Riverside (also called Kacha) Region in district Rajan Pur along the eastern bank of River Indus. Three to five $\mathrm{ml}$ of blood was collected from each animal's jugular vein in a vacuum tube. Each sample was allowed for 1 hour time to coagulate and afterwards applied 3000 RPM centrifugation for 10-15 minute so that serum could be decanted from the sample. The serological assay to detect the occurrence of anti-Toxoplasma antibodies ( $\mathrm{IgG}$ ) was carried out by using "Toxoplasmosis Latex" manufactured by "ANTEC DIAGNOSTIC PRODUCTS-UK. The results were analyzed statistically by applying the statistical tests Chi-square test to compute the correlation via Pearson's test through SSPS version 20.

\section{Results and Discussion}

In the present study, the relationship between habitat variation and occurrence of toxoplasmosis was analyzed and significantly $(\mathrm{P}=0.000)$ varied rates of toxoplasmosis infection were found in three different regions of our study area (Table 1). The results revealed that amongst total 556 small ruminants sampled from the agricultural areas region 212 were found positive for anti-Toxoplasma antibodies with the highest rate of toxoplasmosis $(38.1 \%)$ followed by the animals populated in riverside areas region where, out of 404 total sampled animals 130 were positive for anti-Toxoplasma antibodies showing the infection rate at level of (32.1\%)and with least rate of toxoplasmosis infection were found in the small ruminants reared in Cholistan desert region 35/240 (14.5\%) as shown in Table 1.

Table 1. Relationship between toxoplasmosis and habitat variations.

\begin{tabular}{llll}
\hline Region & $\begin{array}{l}\text { Animals } \\
\text { examined }\end{array}$ & $\begin{array}{l}\text { Animals } \\
\text { positive }\end{array}$ & $\begin{array}{l}\text { Prevalence } \\
\text { (\%) }\end{array}$ \\
\hline Desert Areas & 240 & 35 & 14.58 \\
Agricultural Region & 556 & 212 & 38.12 \\
Riverside Region & 404 & 130 & 32.17 \\
Total & 1200 & 377 & 31.41 \\
\hline
\end{tabular}

Chi-Square $=43.2994$ P-Value $=0.000$

The results demonstrated the significant $(\mathrm{P}-$ Value $=0.000)$ regional variations in prevalence of Toxoplasma infection consistent with (Yang et al., 2013) who reported same picture in China and (Sechi et al., 2013) whose results demonstrated the association between toxoplasmosis and still water sources contaminated by cats' access to water consumed by small ruminants one of the important determinants in three different regions in the present study area.

These variations in infection rates probably could also be related with the humidity being highest in the habitat of small ruminants' flocks populated in the riverside areas in an agreement with Rorman et al. (2006) that the oocysts of T. gondii exhibit a strong structural stability predominantly in warm and humid regions of the world. It is widely accepted view that the oocysts of Toxoplasma have a poor survival in arid and cold climatic conditions (Van der Puijeet al., 2000; Rorman et al., 2006).

The higher rate of toxoplasmosis (38.1\%) (Table 1) in the densely populated Agricultural Region inhabiting animal as compared with the infection rates in the animals reared in desert areas (14.5\%) (Table 1) can be attributed to the presence of higher number of cats in the densely populated localities which can boost the number of oocysts in soil (Petersen and Schmidt, 2003) at a rate of many millions just by single defecation (Lopes et al., 2008) thus causing the contamination of the surrounding habitat (Silva et al., 2001) as is evident from the current study area results.

The ecological factors must be taken into account for the variation in the infection rates amongst the small ruminants reared in different habitats of study area (Dubeyet al., 2004; Meerburg and Kijlstra, 2009). The prevalence rates of toxoplasmosis observed in three regions of our study area 
were in agreement with (Yu et al., 2007) who reported the association between occurrences of $\mathrm{T}$. gondii infection and environmental factors. The similar agreement was found between our findings and (Zewdu et al., 2013).

The rapid sugar industry in Rahim Yar Khan has encouraged the replacement of cotton with Sugarcane and rice crops which increased the humidity in the region suggesting the better chances for the growth of $\mathrm{T}$. gondii in small ruminants and perhaps in the other animal species as well. On the other hand, the animals reared in Cholistan continuously face the stress of the adversely hot summer season along with the scarcity of water and natural vegetation, the mere source of fodder. This is the reason that the nomads of Cholistan desert migrate in the Agricultural areas Region including Sadiqabad, Khan Pur and Liaquet Pur in search of the fodder for their animals particularly on the onset of drought in the dog days of summer season every year. Perhaps during the immigration of the nomad tribes of Cholistan, their small ruminants contract the Toxoplasma infection from the highly infected animals of Agricultural localities.

Furthermore, the Dhands (the seasonal lakes formed by accumulation of rain water) in Cholistan desert, the transient resorts for Siberian migratory birds en route the lakes in the southern limits of Pakistan, are also responsible for the horizontal transmission of T. gondii infection (Cabezon et al., 2011) because, we suspect, the wild cats after feeding on the migratory birds' corps must shed the oocysts in the environment (Amany et al., 2012) which might make their way to the digestive tract of the small ruminants of Cholistan. The stagnant water (Ertug et al., 2005; Sechiet al., 2013) of these Dhands might also be the source of infection as it is shared for drinking by birds as well as small ruminant species simultaneously. This hypothesis is supported by some studies reported in the near past (Taghadosi et al., 2010; Cenci-Goga et al., 2013) providing the evidences of water borne infection of toxoplasmosis.

The Riverside Region showing 32.17\% infection in small ruminants exhibits the peculiar picture of humidity due fluctuating floods in the river Indus. In this region of study area, the animals are faced with the scarcity of food in the monsoon season rainfall and some times, for many months displacement also (Ashraf et al., 2013). During the 2010 monsoon, the standing crop of cotton was devastated by flood in the river Indus. The mass migration of human population with their small ruminants occurred due to that flood thus leading to the exchange of variety of infections between animals of Rahim Yar Khan and those migrated from Kacha area region along the river Indus.

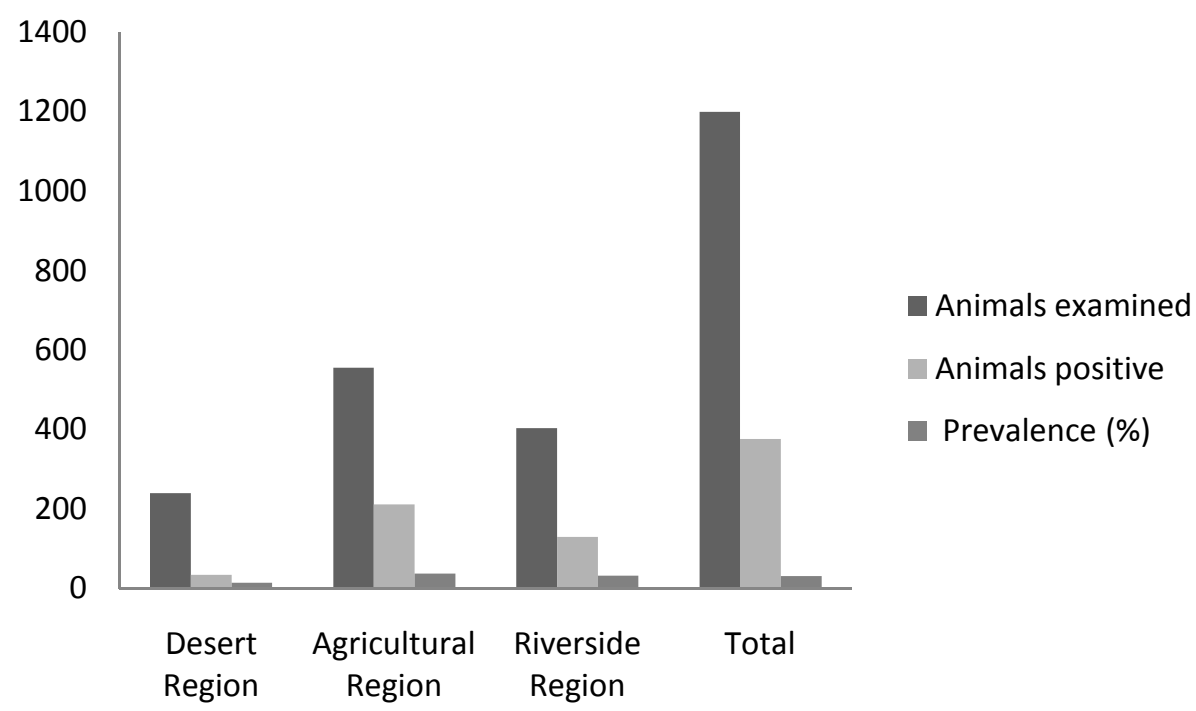

Graph 1. Prevalence of T. gondii infection in varied habitats

\section{Conclusions}

The animals reared in the urban areas with Agri-based population demonstrated the highest rates of seroprevalence of T. gondii (38.1\%) suggesting to the hypothesis that canines must be playing a role in the multiplication of parasite. The least incidence of infections (14.5\%) was noted in the Sand Dunes dwelling small ruminants perhaps due to harshly high temperature in the Cholistan desert that discouraged the sustenance of $\mathrm{T}$. gondii while the infection rates in small ruminants $32.1 \%$ were also influenced by humid environment produced by still water in the region.

\section{Recommendations}

- It was noticed throughout the present study that the farmers prefer to mix farming of livestock species including sheep (Ovis aeries), goats (Capra hircus), buffalo (Bos bubalis) and cows (Bos Taurus) particularly where the pasture grazing adapted for feeding the animals. The standing water must be playing the role in exchange of $\mathrm{T}$. gondii infection 
among different species.

- Therefore, keeping into consideration the horizontal transmission, we suggest the screening of the other livestock species of the study area.

- We also recommend the prompt study to evaluate the infection in humans that might have transmitted by zoonosis.

\section{Author's Contribution}

The blood samples collection from sheep, serological and statistical analyses of data were performed by Saghir Ahmad under the supervision of Prof Dr Zahida Tasawar, Institute of Pure and Applied Biology, Bahauddin Zakariya University, Multan

\section{Acknowledgements}

We are grateful to the Higher Education Commission (HEC), Islamabad, Pakistan for providing funds for financial support/scholarship under Indigenous $5000 \mathrm{PhD}$ Fellowship Program, Batch III, PIN: 063-161120-Bm3-093 for completion of present study.

\section{References}

[1] Akhter, R. and Arshad, M. 2006. Arid Rangelands in the Cholistan Desert (Pakistan). Secheresse., 17: 210-217.

[2] Amany, M., El-Ghany, A. and Merwad, A. M. A. 2012. Epidemiology and Molecular Detection of Zoonotic Toxoplasma gondii in Cat Feces and Seroprevalence of AntiToxoplasma gondii Antibodies in Pregnant Women and Sheep. Life Sci. J.9,133-146.

[3] Ashraf, S., Chuadry, H. R., Farooq, U., Mustafa, Y. S., Fatima, H. and Akhter, S. 2013. Prospective of Dairy Farming in Cholistan. Sci. Int., 25: 345-346.

[4] Aspinall, T. V., Marlee. D., Hyde, J. E. and Sims, P. F. 2002. Prevalence of Toxoplasma gondii in Commercial Meat Products as Monitored by Polymerase Chain Reaction-Food for Thought? Int. J. Parasitol., 32: 1193-1199.

[5] Bueno, J. P., Gozalo, A. Q., Prerez, G. P., Garcia, G. A., Frenandez, E. C. and Mora, L. M. O. 2004. Evolution of ovine abortion associated with Toxoplasma gondii in Spain by different diagnostic techniques. Vet. Parasitol., 121: 33-43.

[6] Buxton, D. S., Maley, W., Wright, S. E., Rodger, S., Bartley, P. and Innes, E. A. 2007. Toxoplasma gondii and ovine toxoplasmosis: New Aspects and Old Story. Vet. Parasitol., 149: $25-28$.

[7] Cabezon, O., García-Bocanegra, I., Molina-Lopez, R., Marco, I. and Blanco, J. M. 2011. Seropositivity and Risk Factors Associated with Toxoplasma gondii Infection in Wild Birds from Spain. Plos One., 6: 1371.

[8] Cenci-Goga, B. T., Ciampelli, A., Sechi, P., Veronesi, F., Moretta, I., Cambiotti, V. and Thompson, P. N. 2013. Seroprevalence and risk factors for Toxoplasma gondii in sheep in Grosseto district, Tuscany, Italy. Vet. Res., 9: 25.
[9] Chacin-Bonilla, L. and Sanchez-Chavez, Y. 2000. Intestinal parasiticinfections, with special emphasis on cryptosporidiosis, in Amerindiansfrom western Venezuela. Am. J. Trop. Med. Hyg., 62: 347-352.

[10] Dabritz, H. A., Miller, M. A., Atwill, E. R., Gardner, I. A., Leutenegger, C. M., Melli, A. C. and Conrad, P. A. 2007. Detection of Toxoplasma gondii like Oocysts in Cat Feces and Estimates of The Environmental Oocyst Burden. J. Amer. Vet. Med. Asso., 231:1676-1684.

[11] Doskaya, M., Degirmenci, A., Cicek, C., Ak, M., Korkmaz, M., Guruz, Y. and Uner, A. 2006. Behavior of Toxoplasma gondii RH Ankara strain tachyzoites during continuous production in various cell lines. Parasitol., 132: 315-319.

[12] Dubey, J. P., Navarro, I. T., Sreekumar, C., Dahl, E., Freire, R. L., Kawabata, H. H., Vianna, M. C., Kwok, O. C., Shen, S. K., Thulliez, P. and Lehmann, T. 2004. Toxoplasma gondii infections in cats from Parana, Brazil: seroprevalence, tissue distribution, and biologic and genetic characterization of isolates. J. Parasitol., 90: 721- 726.

[13] Dubey, J. P. 2009. Toxoplasmosis in sheep-The last 20 years. Vet. Parasitol., 163: 1-14.

[14] Edwards, J. F. and Dubey, J. P. 2013. Toxoplasma gondii abortion storm in sheep on a Texas farm and isolation of mouse virulent atypical genotype T. gondii from an aborted lamb from a chronically infected ewe. Vet. Parasitol.192: 12936.

[15] Ertug, S., Okyay, P., Turkmen, M. and Yuksel, H. 2005. Seroprevalence and risk factors for Toxoplasma infection among pregnant women in Aydin province, Turkey. BMC Pub. Hlth., 5: 66-71.

[16] Ferguson, T. R. 2002. Apicomplexa. J. Parsitol., 18: 355-357.

[17] Gebremedhin, E. Z. and Gizaw, D. 2014. Seroprevalence of Toxoplasma gondii Infection in Sheep and Goats in Three Districts of Southern Nations, Nationalities and Peoples' Region of Ethiopia. W. App. Sci. J., 31: 1891-1896.

[18] Haileleul, N. 2002. Study on Prevalence of GIT Helminthes of Small Ruminants in and Around Wolayta Soddo, Southern Ethiopia. DVM Thesis, Faculty of veterinary medicine, Addis Ababa University, Debre-Zeit. Ethiopia., p. 353.

[19] Hill, D. E. and Dubey, J. P. 2002. Toxoplasma gondii: transmission diagnosis and prevention. Clin. Microbiol. Infect., 8: 634-640.

[20] Innes, E. A., Bartley, P. M., Buxton, D. and Katzer, F. 2009. Ovine Toxoplasmosis. Parasitol., 136: 1884-1894.

[21] Kijlstra, A. and Jongert, E. 2009. Toxoplasma-safe meat: close to reality? Trends Parasitol., 25: 18-22.

[22] Kopecna, J., Jirku, M., Obornik, M., Tokarev, Y. S., Lukes, J. and Modry, D. 2006. Phylogenetic analysis of coccidian parasites from invertebrates: search for missing links. Protist., 157: 173-183.

[23] Lashari, M. H. and Tasawar, Z. 2011. Prevalence of some gastrointestinal parasites in sheep in southern Punjab, Pakistan. Pak. Vet. J., 31: 295-298.

[24] Lhafi, S. K., Mitzscherling, A. T. and Kuhne, M. 2004. Parasitic hazards in meat: a challenge for veterinarians in meat hygiene. Deut. Tierarztl. Woch., 111: 277-281. 
[25] Lopes, A., Cardoso, L. and Rodrigues, M. 2008. Serological Survey of Toxoplasma gondiiinfection in domestic cats from northeastern Portugal. J. Parasitol., 155: 184-189.

[26] Meerburg, B. G. and Kijlstra, A. 2009. Changing climatechanging pathogens: Toxoplasma gondii in North-Western Europe. Parasitol. Res.105: 1447-48.

[27] Nwosu, C. O., Madu, P. P. and Richards, W. S. 2007. Prevalence and seasonal changes in the population of gastrointestinal nematodes of small ruminants in the semi-arid zone of north-eastern Nigeria. Vet. Parasitol., 144:118-124.

[28] Olivier, A., Herbert, B., Sava, B., Pierre, C., John, D. C. and Aline, D. K. 2007 Surveillance and monitoring of Toxoplasma in humans, food and animals: a scientific opinion of the panel on biological hazards. The European Food Safety Association J., 583: 1-64.

[29] Othman, R. A. and Al-Azuheir. 2014. Seroprevalence of Toxoplasma gondii in Goats in Two Districts in Northern Palestine. Walailak J. Sci. Technol.11: 63-67.

[30] Panadero, R., Painceira, A., Lopez, C., Vázquez, L., Paz, A., Díaz, P., Dacal, V., Cienfuegos, S., Fernandez, G., Lago, N., Diez-Banos, P. and Morrondo, P. 2010. Seroprevalence of Toxoplasma gondii and Neosporacaninum in wild and domestic ruminants sharing pastures in Galicia (Northwest Spain). Res. Vet. Sci., 88: 111-115.

[31] Parthiban, M., Govindarajan, R., Manoharan, S., Purushothaman, V., Chandran, N. D. J. and Koteeswaran. A. 2005. Comparative sequence analysis of diagnostic PCR amplicons from Indian sheep pox virus. Vet. Arhiv., 75: 203-209.

[32] Petersen, E. and Schmidt, D. R. 2003. Sulfadiazine and Pyrimethamine in the post-natal treatment of congenital toxoplasmosis: What are the options? Exp.Rev. Anti-infect. Ther.1: 175-182.

[33] Rorman, E., Zamir, C. S., Rilkis, I. and Ben-David, H. 2006. Congenital toxoplasmosis--prenatal aspects of Toxoplasma gondii infection. Reprod. Toxicol., 21: 458 - 472.

[34] Sechi, P., Ciampelli, A., Cambiotti, V., Veronesi, F., Beniamino, T. and Cenci-Goga, B.T. 2013. Seroepidemiological study of toxoplasmosis in sheep in rural areas of the Grosseto district, Tuscany, Italy. Italian J. Anim. Sci., 12: 39.

[35] Sensini, A. 2006. Toxoplasma gondii infection in pregnancy: opportunities and pitfalls ofserological diagnosis. Clncl .Microbiol. Infect., 12: 504-512.

[36] Sevgili, M. C. B., Nalbantoglu, S. and Vatansever, Z. 2005. Determination of Seropositivity for Toxoplasma gondii in sheep in Sanliurfa Province, Turkey. J. Vet. Anim. Sci., 29:107-111.

[37] Siddiki, A. Z., Uddin, M. B., Hasan, M. B., Hossain, M. F., Rahman, M. M., Das, B. C., Sarker, M. S. and Hossain, M. A. 2010. Coproscopic and haematological approaches to determine the prevalence of helminthiasis and protozoan diseases of Red Chittagong Cattle (RCC) breed in Bangladesh. Pak. Vet. J., 30: 1-6.

[38] Silva, J. C., Ogassawara. S., Adania, C. H., Ferreira, F., Gennari, S. M., Dubey, J. P. and Ferreira-Neto, J. S. 2001. Seroprevalence of Toxoplasma gondii in captive neotropical felids from Brazil. Vet. Parasitol., 102: 217-224.

[39] Soares, H. S., Ahid, S. M. M., Bezerra, A. C. D. S., Pena, H. F. J., Dias, R. A. and Gennari, S. M. 2009. Prevalence of antiToxoplasma gondii and anti-Neospora caninum antibodies in sheep from Mossoro, Rio Grande do Norte. Brazil. Vet. Parasitol., 160: 211-214.

[40] Taghadosi, C., Kojouri, G. A. and Taheri, M. A. 2010. Detection of Toxoplasma antibodies in sera of Salmonidae by ELISA. Comp. Clin. Pathol., 19: 203-206.

[41] Van der Puije, W., Bosompem, K., Canacoo, E., Wastling, J. and Akanmori, B. 2000. The prevalence of anti-Toxoplasma gondii antibodies in Ghanaian sheep and goats. Acta Trop.76: 21-26.

[42] Yang, N., Li, H., He, J., Mu, M. and Yang, S. 2013. Seroprevalence of Toxoplasma gondii infection in domestic sheep in Liaoning Province, northeastern China. J. Parasitol., 99: 174-175.

[43] Yu, J., Xia, Z., Liu, Q., Liu, J., Ding, J. and Zhang, W. 2007.Sero-epidemiology of Neosporacaninum and Toxoplasma gondii in cattle and water buffaloes (Bubalus bubalis) in the People's Republic of China. J. Parasitol., 143: 79-85.

[44] Zewdu, E., Agonafir, A., Tessema, T. S., Tilahun, G., Medhin, G., Vitale, M., Di Marco. V., Cox, E., Vercruysse, J. and Dorny, P. 2013. Seroepidemiological study of caprine toxoplasmosis in East and West Shewa Zones, Oromia Regional State, Central Ethiopia.Res. Vet. Sci., 94: 43-8. 